\title{
Influence of Process Parameters of Printing on Mechanical Properties of Plastic Parts Produced by FDM 3D Printing Technology
}

\author{
Petr Vosynek ${ }^{1, a}$, Tomas Navrat ${ }^{1}$, Adela Krejbychova ${ }^{1}$ and David Palousek \\ ${ }^{1}$ Brno University of Technology, Technicka 2, 61669 Brno, Czech Republic
}

\begin{abstract}
Fused Deposition Modelling (FDM) is a fast-growing 3D printing technology. This technology expands rapidly even in households. Most users set print parameters only according to their own experience, regardless of the final mechanical properties. In order to predict the mechanical behaviour of the FDM-printed components, it is important to understand not only the properties of the printing material but also the effect of the printing process parameters on the mechanical properties. Components manufactured by FDM technology have an anisotropic structure, therefore the filling angle, fill shape, air gap, print orientation, and print temperature affect the resulting mechanical properties. This work deals with the change of mechanical properties depending on the setting of the filling angle, the shape of the filling, the orientation of the parts during printing, the influence of the material and pigment manufacturer.
\end{abstract}

\section{Introduction}

In this work, 3D Fusion Deposition Modelling (FDM) technology is used. The essence of this technology is to melt plastic strings through a hot-dip nozzle on a building mat. The height of the applied layer is not the same as the width of the pushed fibre behind the nozzle but is due to the thickness of the nozzle, which is usually $0.4 \mathrm{~mm}$. In the case of more complex shapes of the resulting object, support structures are used. The building and support materials are transported to the print head by system of tubes. The print head comprises a melting chamber where the material is heated and pushed through the nozzle onto the building pad. A drive is used to push the material into the print head so that the material pushes the rotating gear wheels towards the nozzle. The material immediately solidifies on the substrate and, once one layer is applied, the substrate is reduced by the thickness of the layer. Upon completion of printing, the resulting product is broken off from the pad, the supports may be removed mechanically or by a chemical or ultrasonic bath. Among the basic materials used for 3D FDM printing are ABS (Acrylonitrile Butadienstyrene), PLA (Polyactic Acid), PA (Polyamide), PC (Polycarbonate), PET-G (Polyethylene Terephthalate - Glycol) and others, [1].

For our purposes, FLASHFORGE Dreamer was used for printing. This printer has two printheads, so it can print with two printing materials. Printing takes place in a closed chamber that isolates the internal temperature and reduces external temperature influences. The manufacturer promises an accuracy of $0.0025 \mathrm{~mm}$ on the $\mathrm{Z}$ axis and $0.01 \mathrm{~mm}$ on the $\mathrm{XY}$ plane. The maximum print size of this printer is $231 \times 150 \times 140 \mathrm{~mm}$, [2].

\footnotetext{
${ }^{a}$ Corresponding author: vosynek@fme.vutbr.cz
} 
The GCODE file format is used to print the model. The code is generated in FlashPrint, which determines also the print parameters. Several parameters that affect mechanical properties needs to be considered when printing, specifically temperature, print speed, part orientation, infill density, direction, width and raster, overlay size. The parameters are mostly set only based on user experience regardless of the mechanical properties of the printed part. Unlike the injected parts, the FDM-printed parts are anisotropic. If the strength of a component is required, it must be printed in such a way that the mechanical forces are distributed longitudinally along the length of the fibres, [3].

The influence of the direction of the grid and the influence of size of the overlap on the ultimate tensile strength was experimentally investigated in [4] by S. Ahn. The result of this research is that the optimal parameter for joining fibres regarding to mechanical properties is the negative value of the air gap. This gap primarily affects the resulting print strength. Study [4] shows that FDM-printed samples achieved lower tensile strength than samples injected into the mould. This is due to non-homogeneity in the connection between the fibres. This inhomogeneity greatly reduces the effective cross section of the samples. The smallest tensile strength had samples printed with a $90^{\circ}$ infill angle. This is due to the fact, that the force is transmitted only by the connections between the individual fibres, not the fibres themselves. Samples for this experiment were made from ABS P400.

The influence of the orientation of the part during printing and the filling angle on the ultimate tensile strength and Young's modulus is described in [5] (I. Durgun). During the experiment he worked with ABSplus-P430. Samples were printed with five different fill angles $\left(0^{\circ}, 30^{\circ}, 45^{\circ}, 60^{\circ}\right.$ and $90^{\circ}$ ) with three different orientations (horizontally, perpendicularly and vertically). The worst strength results were obtained when the orientation of printed fibres was perpendicular to the pad. The highest tensile strength was achieved by a sample printed at a vertical position with a fill angle of $0^{\circ}$, where the force acts longitudinally along the length of the fibres.

A comprehensive experiment on the mechanical properties of the samples was performed by F. Rayegani [6]. When printing samples, it combined the different orientation of the component $\left(0^{\circ}\right.$ and $\left.90^{\circ}\right)$, the angle $\left(0^{\circ}\right.$ and $\left.45^{\circ}\right)$ and the fill width $(0.2032 \mathrm{~mm}$ and $0.5588 \mathrm{~mm})$ and the air gap $(-0.00254 \mathrm{~mm}$ and $0.5588 \mathrm{~mm})$. Maximum strength was achieved with sample orientation of $0^{\circ}$, fill angle of $45^{\circ}$, fill width of $0.2032 \mathrm{~mm}$ and air gap of $-0.00254 \mathrm{~mm}$. From the results, the air gap can also be greatly influenced by the resulting strength at a positive level much less than that of the negative air gap.

Mechanical properties of parts manufactured by FDM technology may vary according to supplier, colour pigment and additives. Finding a suitable material with high mechanical properties is essential for use in production. At the same time, the process parameters of the 3D printing process are important. For this reason, this article deals with the comparison of the mechanical characteristics of samples made from materials from 2 suppliers, and other influences such as the orientation of the parts during the construction and its filling.

\section{METHODS}

A comparison of mechanical properties was made for PET-G material from two manufacturers Devil Design (DD) and Plastics Mladeč (PM). Mechanical properties were determined by tensile tests.

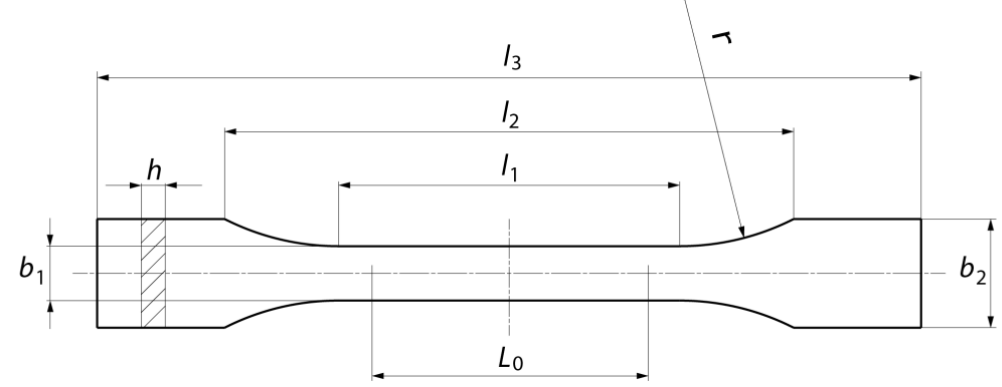

Figure 1. Geometry of specimens 
The shape and dimensions of the specimens were chosen according to ČSN ISO 527-2. With respect to the printer's workspace, a small test specimen (fig. 1) was chosen, with dimensions $l_{3} \geq 75$ $\mathrm{mm}, l_{1}=30 \mathrm{~mm}, r \geq 30 \mathrm{~mm}, l_{2}=58 \mathrm{~mm}, b_{2}=10 \mathrm{~mm}, b_{1}=5 \mathrm{~mm}, h \geq 2 \mathrm{~mm}, L_{0}=25 \mathrm{~mm}$.

Two different types of printing strings were available from each manufacturer. From the manufacturer DD, the material is a transparent colourless (natural - NAT) and a transparent ruby red (RR) material. For the second manufacturer PM: transparent colourless (NAT) and transparent blue (BL). All these materials have a print diameter of $1.75 \mathrm{~mm}$. The samples were designed for comparison the mechanical properties of the material with respect to each manufacturer, the orientation of the printed part, the angle of the raster (fig. 2) and to check the influence of the pigment. All samples were made up of $100 \%$ infill density to be as similar as the injected (casted) parts. In practice, the hexagonal raster (fig. 2) is the most commonly used, with a smaller percent filling to save the material. Therefore, samples with hexagonal raster and $50 \%$ infill density were printed from each manufacturer. For each comparison set, 5 equal pieces were created - in total 12 x $5=60$ samples. The list of the measured samples and sets are shown in tab. 1.

Table 1. List of specimens.

\begin{tabular}{|l|l|l|l|l|l|l|}
\hline Set & Manufacturer & Colour & Infill shape & Raster angle & $\begin{array}{l}\text { Specimen } \\
\text { orientation }\end{array}$ & Infill density \\
\hline $\mathbf{1 .}$ & DD & NAT & line & $45^{\circ} /-45^{\circ}$ & XY horizontal & $100 \%$ \\
\hline $\mathbf{2 .}$ & DD & RR & line & $45^{\circ} /-45^{\circ}$ & XY horizontal & $100 \%$ \\
\hline $\mathbf{3 .}$ & DD & RR & line & $45^{\circ} /-45^{\circ}$ & XZ horizontal & $100 \%$ \\
\hline $\mathbf{4 .}$ & DD & RR & line & $45^{\circ} /-45^{\circ}$ & XZ vertical & $100 \%$ \\
\hline $\mathbf{5 .}$ & DD & RR & line & $0^{\circ} / 90^{\circ}$ & XY horizontal & $100 \%$ \\
\hline $\mathbf{6 .}$ & DD & RR & hexagon & - & XY horizontal & $50 \%$ \\
\hline $\mathbf{7 .}$ & PM & NAT & line & $45^{\circ} /-45^{\circ}$ & XY horizontal & $100 \%$ \\
\hline $\mathbf{8 .}$ & PM & BL & line & $45^{\circ} /-45^{\circ}$ & XY horizontal & $100 \%$ \\
\hline $\mathbf{9 .}$ & PM & BL & line & $45^{\circ} /-45^{\circ}$ & XZ horizontal & $100 \%$ \\
\hline $\mathbf{1 0 .}$ & PM & BL & line & $45^{\circ} /-45^{\circ}$ & XZ vertical & $100 \%$ \\
\hline $\mathbf{1 1 .}$ & PM & BL & line & $0^{\circ} / 90^{\circ}$ & XY horizontal & $100 \%$ \\
\hline $\mathbf{1 2 .}$ & PM & BL & hexagon & - & XY horizontal & $50 \%$ \\
\hline
\end{tabular}

Sets of individual samples were printed at one time so that all samples had the same ambient conditions as temperature or humidity. The specified print parameters are summarized in tab. 2 .

Table 2. Print parameters.

\begin{tabular}{|l|l|}
\hline Extruder temperature & $220^{\circ} \mathrm{C}$ \\
\hline Platform temperature & $65^{\circ} \mathrm{C}$ \\
\hline Thickness of the printed layer & $0.18 \mathrm{~mm}$ \\
\hline Thickness of the first layer & $0.27 \mathrm{~mm}$ \\
\hline Print velocity & $60 \mathrm{~mm} / \mathrm{s}$ \\
\hline
\end{tabular}
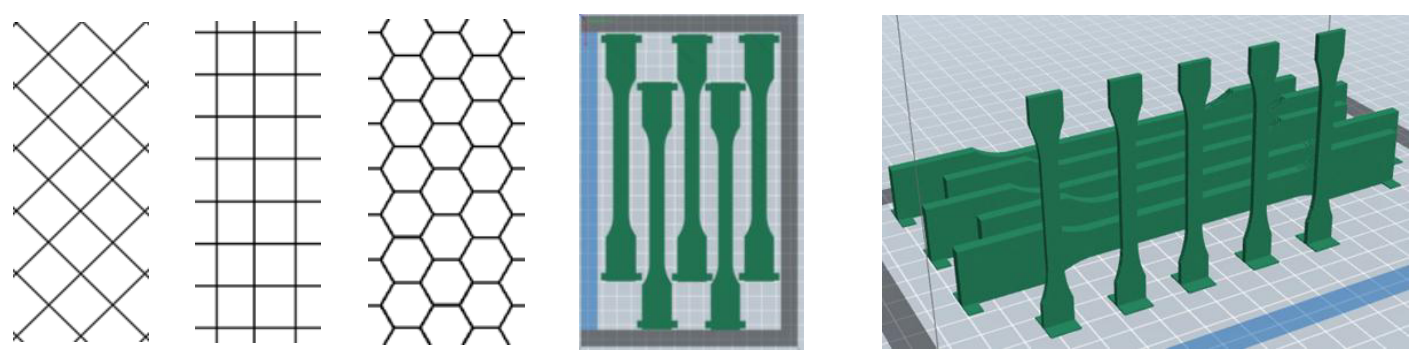

Figure 2. From left to right: types of inner infill $\left(45^{\circ} / 45^{\circ}, 0^{\circ} / 90^{\circ}\right.$, hexagonal), specimen orientation XY horizontal and XZ horizontal + vertical 


\section{Results and discussion}

The Zwick universal test machine with a load cell head up to $22 \mathrm{kN}$ was used for the measurement. Sample loading was carried out at a speed of $3 \mathrm{~mm} / \mathrm{min}$. The force was measured up to break or up to form a neck (for both cases it means significant decrease of the force). Ultimate tensile strength was calculated from the maximum force and the Young's modulus was determined by regression from the stress-strain curve.

In the fig. 3 and fig. 4, there are a comparison of the ultimate tensile strength and Young's modulus for both manufacturers. Each column represents the average strength for all sample sets denoting standard error of the mean. The green columns are represented by Devil Design and Blue Columns by Plastics Mladeč. Alongside each other, there are always samples with the same print parameters:

1) Transparent material, raster $45^{\circ} /-45^{\circ}$, print plane $X Y$; 2) Colour material, raster $45^{\circ} /-45^{\circ}$, print plane XY; 3) Colour material, raster $45^{\circ} /-45^{\circ}$, print plane XZ horizontal; 4) Colour material, raster $45^{\circ} / 45^{\circ}$, print plane $\mathrm{XZ}$ vertical; 5) Colour material, raster $0^{\circ} / 90^{\circ}$, print plane $\mathrm{XY}$; 6) Colour material, raster hexagonal.

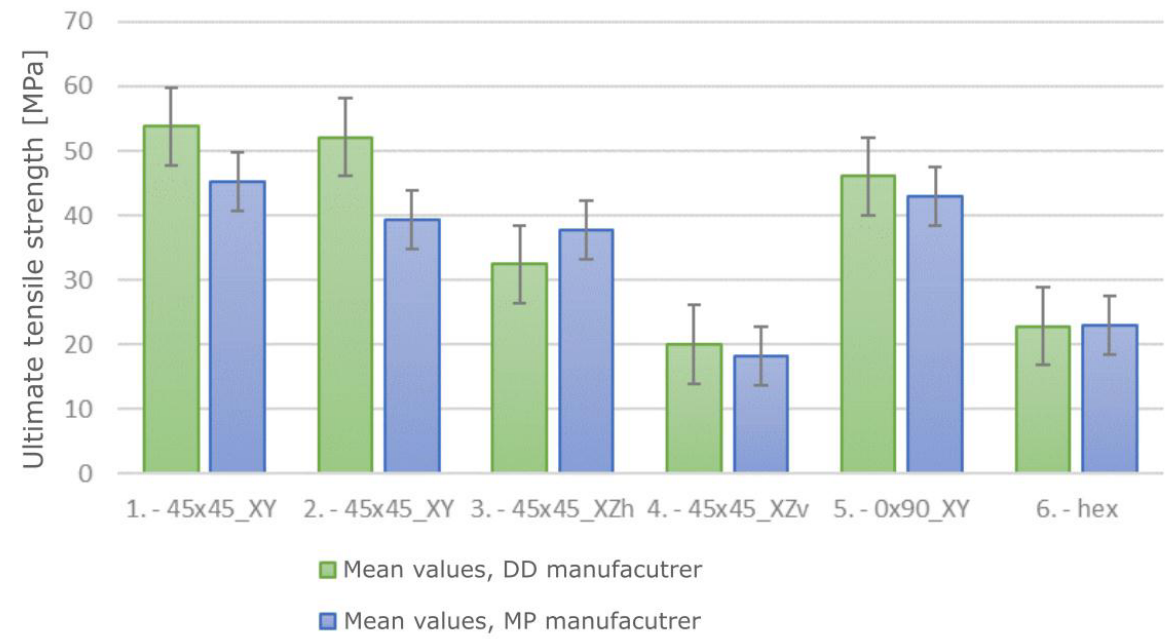

Figure 3. Comparison of ultimate tensile strength between DD a PM.

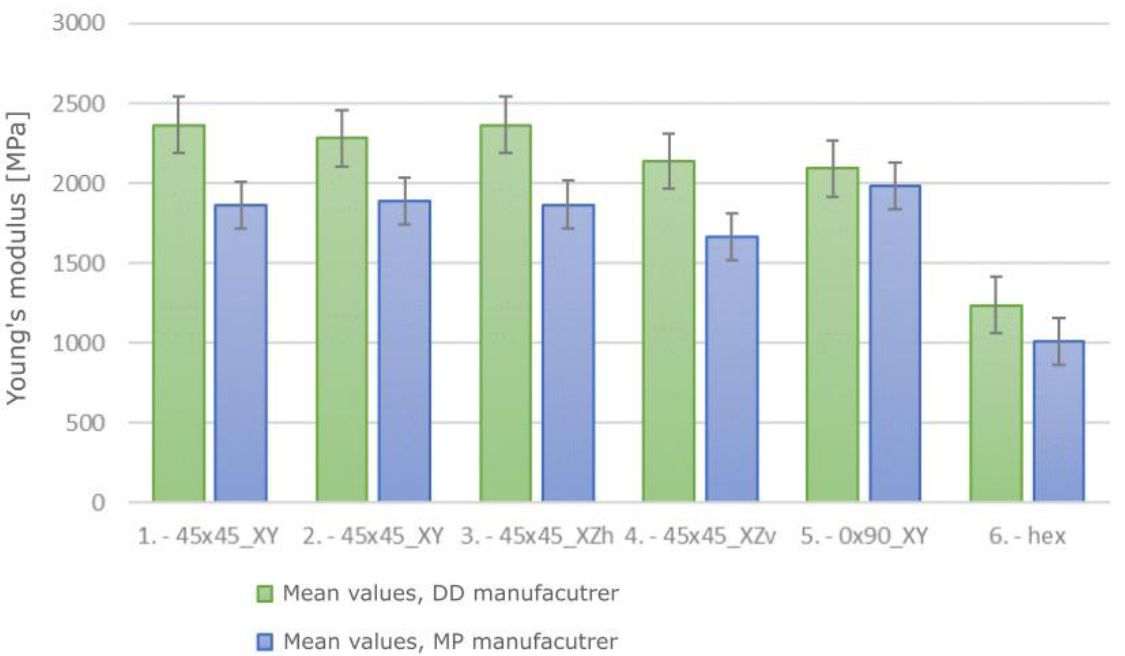

Figure 4. Comparison of Young modulus between DD a PM. 
For samples printed at a $45^{\circ} / 45^{\circ}$ infill angle, the neck was created. The neck was formed at an angle of $45^{\circ}$ in the direction of the fibres and also in the shear plane of the sample. Exceptions were the blue samples from the manufacturer Plastics Mladeč (PM_BL_45x45_XY). Here, the necking were not significand and the end of the test were followed by rupture. This behaviour was probably due to pigment, because natural specimens from the same manufacturer with the same print parameters (PM_NAT_45x45_XY) shows also necking at the end of tensile test.

For all samples other than those mentioned above, there was a rupture. For specimens with a $0^{\circ} / 90^{\circ}$ infill angle and hexagonal infill samples, the angle of fracture was $90^{\circ}$. Similarly, for samples printed vertically in the $\mathrm{XZ}$ plane.

The results of the measurements were statistically processed using the Minitab program. At 5\% significance levels, we can assume that the data follows normal distribution (Anderson-Darling normality test). The individual sets are independent of one another (unpaired). To compare the different sets, we used the Two Sample t-test parameter test. Table 3 summarizes the percentage differences in mean values of ultimate tensile strength and Young's modulus.

Table 3. Comparison of mean values of ultimate strength and Young modulus for given sets of samples (with p-values):

\begin{tabular}{|c|c|c|c|}
\hline \multirow{2}{*}{\multicolumn{2}{|c|}{$\begin{array}{lllll}\text { Sets of samples } & - & \text { comparison } & \text { between } \\
\text { manufacturers }\end{array}$}} & \multicolumn{2}{|c|}{$\Delta(\%)$} \\
\hline & & Young modulus & $\begin{array}{l}\text { Ultimate } \\
\text { strength }\end{array}$ \\
\hline DD_NAT_45x45_XY & PM_NAT_45x45_XY & $\begin{aligned} & -21,1 \\
p & <0,0005\end{aligned}$ & $\begin{array}{c}-16,1 \\
p<0,0005\end{array}$ \\
\hline DD_RR_45x45_XY & PM_BL_45x45_XY & $\begin{aligned} & -17,2 \\
p & <0,0005\end{aligned}$ & $\begin{array}{c}-24,6 \\
p=0,002\end{array}$ \\
\hline DD_RR_45x45_XZh & PM_BL_45x45_XZh & $\begin{aligned} & -21,1 \\
p & <0,0005\end{aligned}$ & - \\
\hline DD_RR_hex & PM_BL_hex & $\begin{array}{c}-18,4 \\
p=0,011\end{array}$ & - \\
\hline \multicolumn{4}{|c|}{ Sets of samples - pigment influence } \\
\hline DD_NAT_45x45_XY & DD_RR_45x45_XY & - & $\begin{array}{c}-3,0 \\
p=0,029\end{array}$ \\
\hline PM_NAT_45x45_XY & PM_BL_45x45_XY & - & $\begin{array}{c}-12,9 \\
\mathrm{p}=0,028\end{array}$ \\
\hline \multicolumn{4}{|c|}{$\begin{array}{l}\text { Sets of samples - infill angle and infill shape } \\
\text { influence }\end{array}$} \\
\hline DD_RR_45x45_XY & DD_RR_0x90_XY & $\begin{array}{c}-8,3 \\
p=0,001\end{array}$ & $\begin{array}{c}-11,7 \\
p<0,0005\end{array}$ \\
\hline DD_RR_45x45_XY & DD_RR_hex & $\begin{aligned} & -45,8 \\
p & <0,0005\end{aligned}$ & $\begin{aligned} &-56,3 \\
& p<0,0005\end{aligned}$ \\
\hline PM_BL_45x45_XY & PM_BL_hex & $\begin{aligned} & -46,6 \\
\mathrm{p} & <0,0005\end{aligned}$ & $\begin{array}{c}-41,6 \\
p=0,001\end{array}$ \\
\hline \multicolumn{4}{|c|}{ Sets of samples - sample orientation influence } \\
\hline DD_RR_45x45_XY & DD_RR_45x45_XZh & - & $\begin{array}{c}-37,8 \\
p=0,001\end{array}$ \\
\hline DD_RR_45x45_XY & DD_RR_45x45_XZv & - & $\begin{aligned} & -61,7 \\
p & <0,0005\end{aligned}$ \\
\hline DD_RR_45x45_XZh & DD_RR_45x45_XZv & - & $\begin{array}{c}-38,4 \\
p=0,003\end{array}$ \\
\hline PM_BL_45x45_XY & PM_BL_45x45_XZv & $\begin{array}{c}-11,8 \\
p=0,004\end{array}$ & $\begin{aligned} & -53,6 \\
p & <0,0005\end{aligned}$ \\
\hline PM_BL_45x45_XZh & PM_BL_45x45_XZv & $\begin{array}{c}-10,8 \\
p=0,022\end{array}$ & $\begin{aligned} & -51,7 \\
p & <0,0005\end{aligned}$ \\
\hline
\end{tabular}

\section{Conclusions}


From the analysis of the results it is obvious that the greatest influence on the resulting strength is the orientation of the part during printing. The highest tensile strength with respect to the orientation of the component is achieved by XY-printed samples and the lowest samples printed vertically in the XZ plane, which do not reach even $50 \%$ of the tensile strength value of samples printed in the XY plane. Furthermore, the tensile strength significantly affects the shape of the infill, where the hexagonal shape is less, but the percent filling of the samples plays a large role here. Hexagonal infill samples are printed with $50 \%$ infill density, and $23 \%$ less material is used than other samples with $100 \%$ infill density.

For Devil Design manufacturer, the effect of raster orientation was noted, with samples built with the $45^{\circ} / 45^{\circ}$ raster ultimate tensile strength being $12 \%$ higher than those with a $0^{\circ} / 90^{\circ}$ raster. For Plastice Mladeč, this influence was statistically insignificant. Better mechanical properties were measured on samples from Devil Design, where the tensile strength and the Young's modulus were about $20 \%$ higher than those of Plaster Mladeč's manufacturer.

The influence of the pigment was different according to the manufacturer. For the natural (colourless) material from Devil Design, the tensile strength was $3 \%$ higher than that of the red material, at Plastice Mladeč, the difference between the tensile strength between natural and blue material was nearly $13 \%$.

\section{Acknowledgement}

Financial support through the project NETME CENTRE PLUS (LO1202) by the Czech Ministry of Education, Youth and Sports under the "National Sustainability Programme I" is gratefully acknowledged.

\section{References}

1. FDM technologie (Fused Deposition Modeling). 3D inventor blog, online, (2016)

2. Flashforge Dreamer Dual Extrusion 3D Printer. FLASHFORGE USA, online, (2015)

3. What is Design for Additive Manufacturing. ENGINEERS rule: Technology for Design and Engineering online, (2016)

4. S. H. Ahn, M. Montero, D. Odell, S. Roundy, P. K. Wright, Anisotropic material properties of fused deposition modeling ABS. Rapid Prototyping Journal, 8(4): 248-257, (2002)

5. I. Durgun, R. Ertan, Experimental investigation of FDM process for improvement of mechanical properties and production cost. Rapid Prototyping Journal, 20(3), 228-235, (2014)

6. F. Rayegani, G. C. Onwubolu. Fused deposition modelling (FDM) process parameter prediction and optimization using group method for data handling (GMDH) and differential evolution (DE). The International Journal of Advanced Manufacturing Technology, 73(1-4), 509-519, (2014) 